\title{
Overestimated water storage
}

To the Editor - Pokhrel et al. ${ }^{1}$ attempt to estimate sea-level change caused by changes in terrestrial water storage, using an integrated water resources assessment model. I suggest that they have substantially overestimated the contribution of terrestrial water storage to sea-level change, because their model assumptions are unrealistic.

First, the model used by Pokhrel et al. does not actually simulate groundwater flow processes. Instead, all groundwater use is assumed to be unsustainable and therefore to equate to groundwater depletion. This assumption contradicts the principle that well withdrawals from an aquifer are partly or even mostly balanced by increased recharge and decreased discharge, induced by lowered water levels in the aquifer, and do not correspond to decreased storage ${ }^{2,3}$. Furthermore, the fraction of pumpage derived from storage decreases with time ${ }^{2,3}$. For the US, with its broad spectrum of aquifer types, boundary conditions and types of water uses, total groundwater withdrawals amounted to $5,340 \mathrm{~km}^{3}$ over the period 1950 to $2005^{4}$. Cumulative groundwater depletion for that period was about $823 \mathrm{~km}^{3}$ (ref. 5), only $15 \%$ of the total extractions. If a percentage of 15-20\% reflects average global conditions, then the assumption by Pokhrel et al. that all pumpage is equivalent to depletion could lead to an overestimation of global depletion by a factor of 5 to 7 .

Secondly, Pokhrel et al. derive a cumulative total of $18,000 \mathrm{~km}^{3}$ of groundwater depletion from 1950-2000.
This is grossly out of bounds with what has been observed. The largest, and best documented case of depletion in one aquifer system is the High Plains (Ogallala) aquifer in the central US, where the cumulative groundwater depletion amounted to $243 \mathrm{~km}^{3}$, or $28 \%$ of extractions, for 1950 to $2000^{6}$. Another 50 to 70 similarly depleted systems simply do not exist throughout the world.

Finally, their consideration of reservoir seepage to groundwater is also flawed. They assume that seepage losses directly equate to a volumetric increase in terrestrial storage, using a model of total water seepage increasing indefinitely as $\sqrt{t}$. This model works if the aquifer is infinite in areal extent and the rising groundwater levels do not encounter any interfering boundary conditions ${ }^{7}$. Both assumptions are, however, unrealistic: aquifers are not infinite, and interfering boundaries, such as a river valley below the dam, are almost always close by. Pokhrel et al. estimate that reservoir storage attributed to seepage is about $50 \%$ of reservoir capacity. One of the few studies documenting reservoir bank storage indicates that increased groundwater storage adjacent to the Hungry Horse Reservoir, Montana, represents only about $7 \%$ of the reservoir capacity $^{8}$. If this difference of a factor of 7 holds more generally, the computed effect of reservoir storage on sea-level change would be much smaller. Storage increases in aquifers adjacent to surface reservoirs are mostly local in nature ${ }^{9}$ and will often stabilize within a few months or years following the filling of the reservoir. After a reservoir starts to fill, adjacent groundwater levels rise and the seepage into the aquifer will become increasingly balanced by increases in groundwater discharge, which limits increases in groundwater storage as the groundwater flow system attains a new equilibrium condition. In many areas, groundwater seepage into certain parts of a reservoir will be large relative to seepage losses out of other parts ${ }^{10}$.

I conclude that Pokhrel et al. ${ }^{1}$ have substantially overestimated storage changes from groundwater depletion and reservoir seepage losses, and their model is not valid for these purposes.

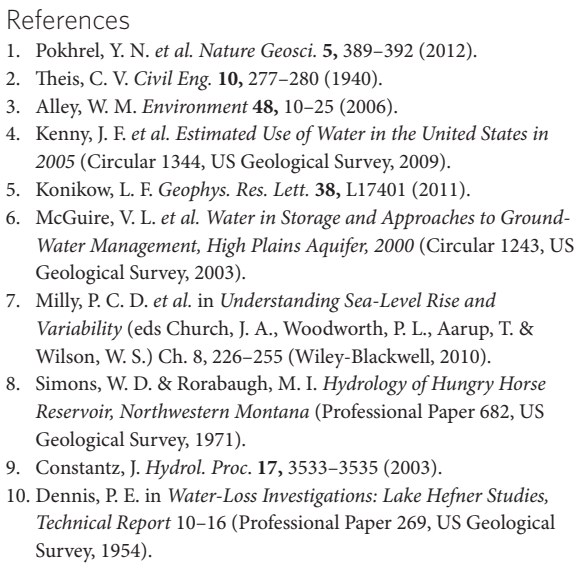

Leonard F. Konikow

US Geological Survey, 431 National Center,

Reston, Virginia 20192, USA.

e-mail: Ikonikow@usgs.gov
Authors' reply - Konikow argues that our model simulation ${ }^{1}$ overestimated the contribution of groundwater depletion to sea-level change, partly on the grounds of a comparison with his own estimate that is based on limited data of groundwater depletion ${ }^{2}$. We acknowledge that our model estimate of unsustainable groundwater use is based on several unavoidable assumptions and hence contains uncertainties, which were clearly stated in our Letter. However, we disagree with Konikow's suggestion that our approach is flawed and that the results obtained are out of bounds.

First, according to Konikow, our model assumes that "all groundwater use is unsustainable and therefore equates to groundwater depletion". This is incorrect because we estimated the unsustainable groundwater use as the difference between the total water demand and the supply from near-surface sources ${ }^{3}$. The renewable groundwater is implicitly included in the withdrawal from near-surface sources. Moreover, this approach dynamically accounts for irrigation return flows and the resulting increase in soil water and subsurface runoff - that is, the increased availability of near-surface water.

Second, although soil moisture variation in the top $4 \mathrm{~m}$ is resolved, we agree that our model, as well as other published studies $^{4}$, does not explicitly simulate the well hydraulics associated with groundwater pumping. Instead, the demand-supply approach is used to estimate unsustainable groundwater use; albeit simple, this approach is commonly conceived as the current state-of-the-art method in globalscale water resources modelling ${ }^{3,5}$. Given that the finest spatial resolution of the models is $\sim 0.5^{\circ}$ and that the models are one-dimensional in nature, this is currently the only practical approach; it is difficult to parameterize all the fine-scale groundwater processes as suggested by Konikow.

Third, Konikow's estimate ${ }^{2}$ of global groundwater depletion relies on the 